\title{
Born in the Ear Canal: Tick Larva on the Eardrum
}

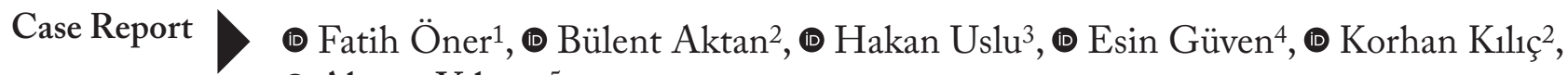 \\ (1) Ahmet Y1lmaz \\ ${ }^{1}$ Department of Otorhinolaryngology, Erzurum Regional Training and Research Hospital, Erzurum, Turkey \\ ${ }^{2}$ Department of Otorhinolaryngology, Atatürk University Faculty of Medicine, Erzurum, Turkey \\ ${ }^{3}$ Department of Microbiology, Atatürk University Faculty of Medicine, Erzurum, Turkey \\ ${ }^{4}$ Department of Parasitology, Atatürk University, Faculty of Veterinary Medicine, Erzurum, Turkey \\ ${ }^{5}$ Department of Medical Laboratory Techniques, Atatürk University Vocational School of Health Services, Erzurum, \\ Turkey
}

This case was presented as a poster at the $18^{\text {th }}$ International Parasitology Congress (Denizli, 2013).

\section{ORCID ID of the authors:}

F.Ö. 0000-0001-6195-3110;

B.A. 0000-0002-6939-7961;

H.U. 0000-0003-1478-7441;

E.G. $0000-0001-7067-8819$;

K.K. 0000-0001-6048-034X;

A.Y. $0000-0002-2350-1516$.

Cite this article as: Öner F, Aktan B, Uslu H, Güven E, KIlıç K, Yılmaz A. Born in the Ear Canal: Tick Larva on the Eardrum. Turk Arch Otorhinolaryngol 2021; 59(2): 150-3.

Corresponding Author: Fatih Öner; fatihoner.ent@gmail.com

Received Date: 01.02 .2021 Accepted Date: 25.04.2021

Content of this journal is licensed under a Creative Commons Attribution 4.0 International License. Available online at www.turkarchotolaryngol.net (c) (i) \$

DOl: 10.4274/ta0.2021.2021-1-12
We report the case of a 54-year-old woman who presented to the ear, nose, and throat (ENT) outpatient clinic with hearing loss, tinnitus, and fullness in her right ear. In the first clinical examination, a pouch hanging in the anterior upper quadrant was detected in the tympanic membrane of the right ear. A tick larva was found in the cyctic lesion located on the tympanic membrane. Our case was unique due to this unexpected diagnosis.

Keywords: External ear canal, tympanic membrane, foreign body, ticks, larvae, case report

\section{Introduction}

In the ear, nose, and throat (ENT) practice, foreign bodies in the external auditory canal (EAC) are commonly seen. Beads, plastic toy parts, pebbles, corn kernels, toy parts, candle wax, food, paper, button batteries, cotton, metal balls, pen tips, and erasers are known aural foreign bodies $(1,2)$. Sometimes live foreign bodies, such as flies and ticks, can also enter the EAC. While vector-borne infections are among the leading causes of both human and animal diseases, ticks are one of the most critical vector groups. Ticks can mediate some diseases (CrimeanCongo hemorrhagic fever, Lyme disease) as vectors and cause some complaints (earache, fullness, hearing loss, tinnitus, painful otitis externa) when they settle in the EAC (3).

\section{Case Presentation}

A 54-year-old woman was admitted to the ENT outpatient clinic with tinnitus, humming, fullness, and hearing loss in her right ear. The patient did not have any problems with her right ear until an ache, followed by complaints like fullness, increasing hearing loss, tinnitus emerged abruptly. In the first clinical examination, a pouch hanging on the anterior upper quadrant was detected in the tympanic 
membrane of the right ear. The pouch was a $5 \times 4 \mathrm{~mm}$ cystic bag filled with fluid in constant motion (Figure 1).

The patient's medical history revealed that she was diagnosed with glomus jugulare in her left ear and was treated with radiotherapy. Deafness was found in the left ear after radiotherapy and the patient had not been followed-up in the past two years. The left EAC and tympanic membrane were found normal in otoscopic examination.

In addition to the constantly moving fluid in the pouch, there was an increase in the vascularization of the rest of the tympanic membrane, and its color was matte. Minimal fluid (air-fluid level) existed behind the tympanic membrane. Audiometric analysis revealed a conductive hearing loss in the right ear, audiogram, air $46 \mathrm{~dB}$, and bone $16 \mathrm{~dB}$. In the left ear, air $97 \mathrm{~dB}$ and bone $74 \mathrm{~dB}$ were found (sensorineural hearing loss associated with the glomus tumor and radiotherapy). In the tympanometric assessment, there were type $\mathrm{B}$ and $\mathrm{A}$ tympanograms respectively for the right and left ears.

The patient was hospitalized with otitis media and a preliminary diagnosis of tumor of vascular origin attached to the eardrum in the middle ear or epidermoid cyst of the tympanic membrane. The patient was given antibiotic (ampicillin/sulbactam) and topical nasal decongestant (oxymetazoline hydrochloride) as treatment. The temporal bone was scanned with computed tomography to evaluate the middle ear structures and the examination revealed no pathology. The complaints of the patients did not decrease but increased in the 48 hours after the treatment was started. In examination, the sac was enlarged and pronounced. On the third day of hospitalization, severe tinnitus and ear pain emerged in the patient's right ear. Otoscopic examination revealed that the cystic pouch on the tympanic membrane had burst, and an arthropod was moving in the EAC. The arthropod was carefully removed from the EAC and placed

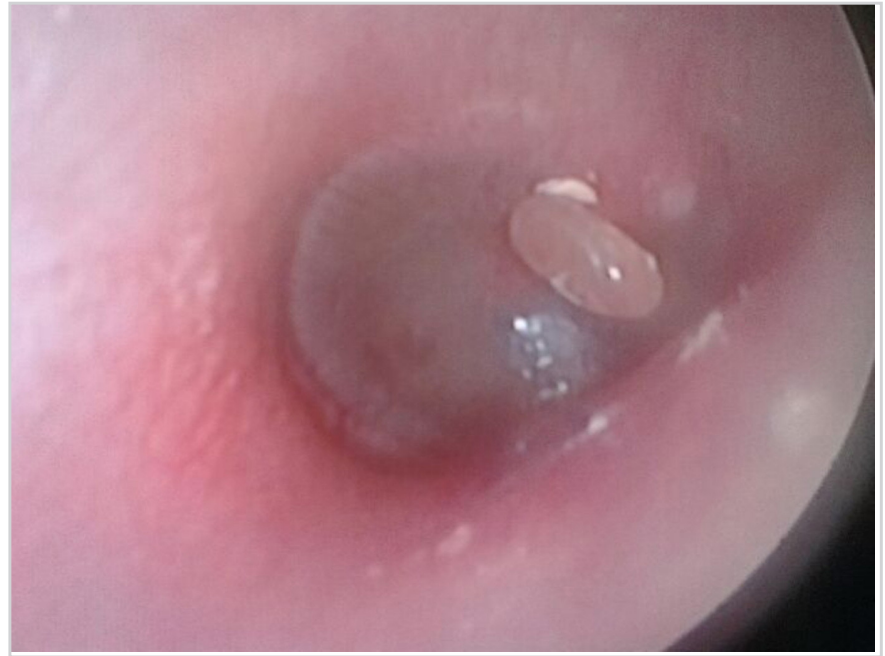

Figure 1. Tick larva on the eardrum in a glass jar (Figure 2). The patient's tympanic membrane was intact, and all complaints, tinnitus, humming, and hearing loss regressed.

The tympanic membrane was normal two days after the arthropod was removed. New audiometric analysis revealed normal hearing in the right ear with type A tympanogram. The patient was referred to the department of infectious diseases for Crimean-Congo hemorrhagic fever. All the hematologic and biochemical examinations were normal.

The arthropod was sent to the departments of parasitology and medical microbiology of the Veterinary Faculty for parasitological analysis. Parasitological analysis defined the arthropod as a tick due to its specular formation and four pairs of legs (Figure 3). The tick was in the latest stage of the first nymph (the juvenile stages of life) and nearly past the second nymph stage without bloodsucking. After its subtype was defined, the tick was released to the natural environment and no more examinations were performed.

\section{Discussion}

Foreign bodies in the EAC are not rare entities among otolaryngologic diseases. It is especially common in pediatric age groups. Unlike children and mentally disabled people, most normal adults know the etiology of the foreign body and consult a doctor without complaints arise. Such cases can remain asymptomatic, or cause earache, otitis externa,

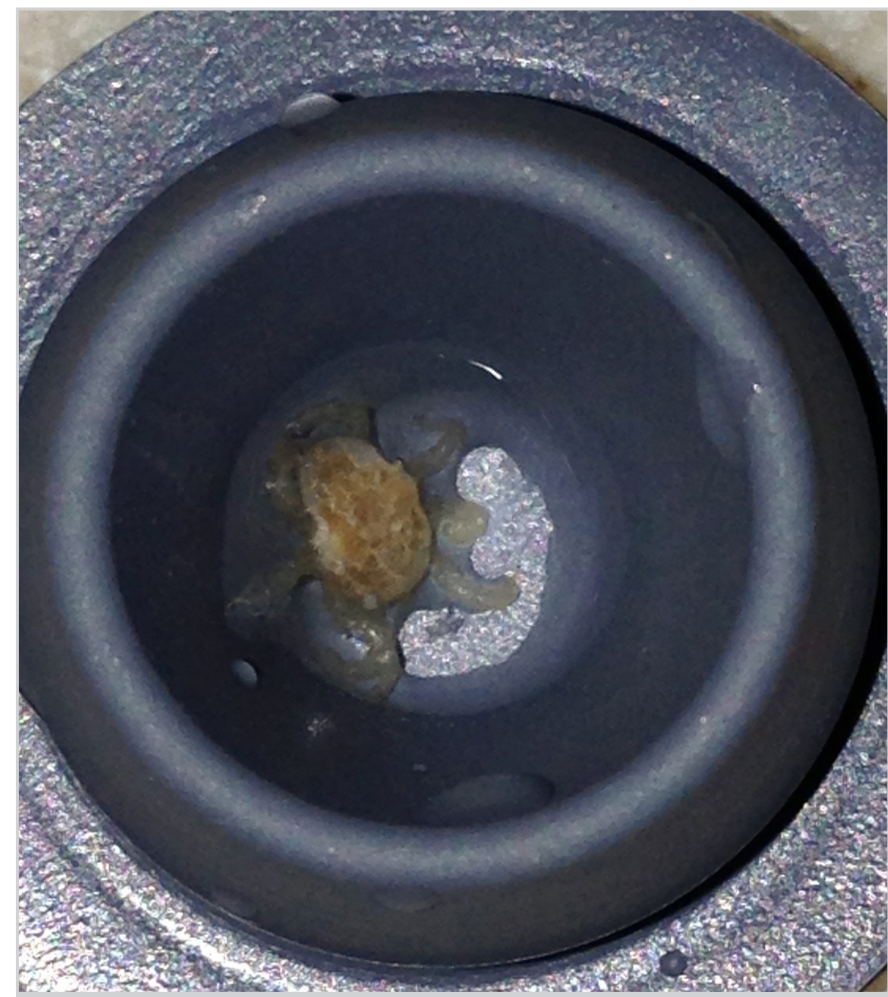

Figure 2. The young larva, which has just come out of the pouch, was taken to a transport container 


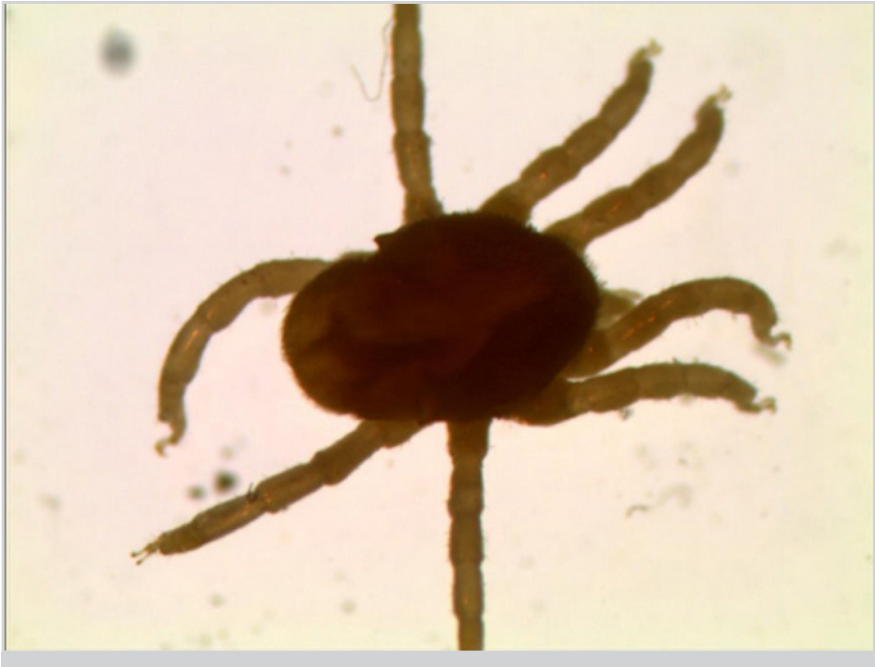

Figure 3. Image of nymph not yet fed under a magnifying glass

purulent drainage from the affected ear, hearing loss, hyperacusis, itching, fullness, tinnitus, or feeling of a foreign body in the ear (4).

Sometimes they can lead to more severe complications such as advanced sensorineural hearing loss, suppurative labyrinthitis, and osteomyelitis (5). A wide variety of foreign bodies, such as beads, batteries, fruit seeds, paper, grass have been removed from the ear canal. Although rare, pests such as ticks, flies, and ants can also enter the EAC. It should be noted that ticks, as was the case of our patient, can release their larvae in the external ear canal. The EAC is an ideal place for ticks to suck blood or leave their larvae. When clinicians identify the presence of tick larva, they should not try to pull it with tools like punch forceps, but gently cut the cyst wall and try to remove the content without damaging the eardrum.

Spinose ticks, which consume blood while in the external ear canal, can cause irritation, inflammatory reaction, tissue necrosis, and bacterial infection. It is reported that a fouryear-old female child had difficulty chewing and swallowing, hoarseness, hypernasal speech, and hypersalivation because of an oropharyngeal muscle weakness as a result of tick bite. Muscle weakness was seen due to the passage of neurotoxins secreted by the tick along the esophagus (6).

When tick eggs grow in the place they are laid, they can resemble a cyst. In our case, that the tick larva was attached to the eardrum led us to consider tympanic membrane cysts in differential diagnosis. Most of the cysts defined in the middle ear contain cholesteatoma and are associated with a history of infection or with iatrogenic effects (7). The presence of epidermal/epithelial inclusion cysts on the tympanic membrane is defined as a possible iatrogenic lesion that occurs only after myringoplasty or infection (8-10). In our case, however, we report that it can also occur due to tick larvae. We hope that this first-ever report about an unusual entity, which may go unnoticed due to its rare characteristics, will provide a key to clinicians when examining patients presenting with similar complaints.

Acknowledgements: We thank Professor Armağan Hayırlı, for his grammatical editing contributions in this article.

Informed Consent: Written and verbal consent was obtained from the patient.

Peer-review: Externally peer-reviewed.

\section{Authorship Contributions}

Surgical and Medical Practice: F.Ö., B.A., K.K., Conception: F.Ö., B.A., K.K., Design: F.Ö., H.U., Data Collection and/ or Processing: F.Ö., B.A., H.U., E.G., K.K., A.Y., Analysis and/or Interpretation: F.Ö., B.A., H.U., E.G., K.K., A.Y., Literature Review: F.Ö., Writing: F.Ö., B.A., H.U., E.G., K.K., A.Y.

Conflict of Interest: The authors have no conflicts of interest to declare.

Financial Disclosure: The authors declared that this study has received no financial support.

\section{Main Points}

- The appearance of ticks in the external ear canal is a common clinical condition.

- Tick larva on the eardrum, however, is a rare entity mimicking a membrane cyst or middle ear pathology.

- It can be confused with a tympanic membrane cyst and should be kept in mind in diagnosis, as we found in our case.

\section{References}

1. Johari HH, Moses SS, Salim R, Hashim SSM. Removal of superglue from the ear with over-the-counter Cerumol ear drops. B-ENT 2017; 13: 59-61. [Crossref]

2. Heim SW, Maughan KL. Foreign bodies in the ear, nose, and throat. Am Fam Physician 2007; 76: 1185-9. [Crossref]

3. Diseases Transmitted by Ticks, Centers for Disease Control and Prevention, National Center for Emerging and Zoonotic Infectious Diseases (NCEZID), Division of Vector-Borne Diseases (DVBD). [April 2020]. Available from: https://www.cdc.gov/ticks/diseases/ index.html [Crossref]

4. Oyama LC. Foreign bodies of the ear, nose and throat. Emerg Med Clin North Am 2019; 37: 121-30. [Crossref]

5. Woodley N, Mohd Slim MA, Tikka T, Locke RR. Not 'just' a foreign body in the ear canal. BMJ Case Rep 2019; 12: e229302. [Crossref] 
6. Bör Ö, Yakut A, Kırel B, Özüdoğru E. Oropharyngeal muscle weakness due to the tick bite. Turkiye Klinikleri J Pediatr 1998; 7: 204-5. [Crossref]

7. Pahor AL. Tympanic membrane epidermoid following head injury. Ear Nose Throat J 1978; 57: 330-2. [Crossref]

8. Nussbaum MA. Epidermoid cyst of the tympanic membrane. J Laryngol Otol 1970; 84: 733-5. [Crossref]
9. Merifield DO. Epithelial cyst as a complication of stapedectomy: a case report. Laryngoscope 1965; 75: 1893-6. [Crossref]

10. Ramírez-Camacho R, Salas I, Trinidad A, Villarreal IM. Noncholesteatomatous cyst of the tympanic membrane: a nonpublished entity? Case Rep Otolaryngol 2015; 2015: 187187. [Crossref] 